\title{
Nanoscale Deformation and Nanomechanical Properties of Soft Matter Study Cases: Polydimethylsiloxane, Cells and Tissues
}

\author{
Costas Charitidis \\ School of Chemical Engineering, National Technical University of Athens, 9 Heroon, Polytechniou st., Zografos, 15780 Athens, Greece \\ Correspondence should be addressed to Costas Charitidis, charitidis@chemeng.ntua.gr \\ Received 10 April 2011; Accepted 5 May 2011 \\ Academic Editors: J. B. Edel and Y. Song \\ Copyright () 2011 Costas Charitidis. This is an open access article distributed under the Creative Commons Attribution License, \\ which permits unrestricted use, distribution, and reproduction in any medium, provided the original work is properly cited. \\ Nanoindentation technique was used to investigate the nanomechanical behaviour of different soft materials. Polydimethylsiloxane \\ (PDMS), cells and tissues were examined. The nanomechanical properties (with loading rate and creep study), namely, the \\ hardness $(H)$ and the elastic modulus $(E)$ of PDMS, were determined. A classical Hertzian contact analysis was also performed \\ in order to obtain values of $E$. Moreover, the plastic deformation where no load had yet been applied to PDMS was investigated \\ (zero load plastic deformation). Finally, the difficulties of measuring the nanomechanical properties $(H \& E)$ of cells and tissues \\ were evaluated, showing the need for a modification of the current experimental protocols for preparing and mechanically testing \\ in a mode that maintains their structure and their biological functioning in order to make indentation results more reproducible. \\ Additionally, finite element method is used in order to simulate the nanoindentation of PDMS in correlation with experimental \\ data.
}

\section{Introduction}

Soft matter (or soft condensed matter) refers to a group of systems that includes polymers, colloids, amphiphiles, membranes, micelles, emulsions, dendrimers, liquid crystals, polyelectrolytes, and their mixtures. Soft matter structures usually have structural scales in the region from a nanometer to several hundred nanometers and thus fall within the domain of "nanotechnology," The soft matter length scales are often characterized by interactions that are of the order of thermal energies so that relatively small perturbations can result in dramatic stfructural changes. From an industrial point of view, soft matter is important since it exhibits promising industrial growth and helps in understanding the intricacies of the life processes (paints, surfactants, porous media, plastics, pharmaceuticals, ceramic precursors, textiles, proteins, polysaccharides, blood, etc.). Additionally, soft materials have a wide range of applications in bioengineering, electronics, and medicine [1].

Determination of the mechanical properties of soft materials is a complicated process due to their heterogeneous nature. Therefore, standard characterization methods, such as compression and tensile tests, may not be applicable due to inadequate sample dimensions. In this regard, techniques that allow the examination of the mechanical properties on a much reduced scale are needed. Nanoindentation is a technique which has been widely used to characterize the mechanical properties of materials at surface or subsurface. More specifically, through the nanoindentation experiment, the hardness $(H)$, the elastic modulus $(E)$, and other mechanical properties can be determined from very small volumes of materials. The high spatial resolution of nanoindentation allows local testing of mechanical properties of soft matter that is not possible using macroscale techniques. For this reason, the application of nanoindentation to soft materials has increased over recent years [2].

Polymers, a major category of soft materials, are typically much more compliant compared to hard materials, with $E$ ranging from a few GPa for common glassy polymers to a few $\mathrm{MPa}$ or lower for rubbery polymers [3]. Considerable uncertainties arise when applying the nanoindentation technique to polymers with $E$ below $5 \mathrm{MPa}$ or adhesive polymers (e.g., Polydimethylsiloxane (PDMS) ) [4]. Polydimethylsiloxane, a clear elastomer, is a common material used in many applications in bioengineering, electronics, and microelectromechanical systems because it is biologically inert, gas 
permeable, insulator, and good for rapid prototyping of devices [5]. The advantages of PDMS also include its good electrical properties, low surface energy, isotropic and homogeneous properties. Polydimethylsiloxane is also thermally stable and performs well over a wide range of temperatures [6]. Its nanomechanical properties are of great interest, for example in applications involving pressure support or fluid manipulation, and have to be carefully validated, because exposure to chemicals and temperature changes may cause their variation.

Biological materials, such as cells and tissues, can be classifiable as soft materials. The mechanical characterization of cells and tissues is of utmost importance in clinical medicine and the field of biomaterials. Considerable research relating to the links between the biomechanical properties of cells and human diseases has been carried out [7-11]. A change in the mechanical properties of cells has recently emerged as an indication of disease, although malignant and benign cells have similar morphological features. Thus, mechanical elucidation is crucial for realizing advances in diagnostics and therapeutics [12].

There are critical issues associated with applying nanoindentation to soft materials. Soft materials exhibit viscoelastic behavior, and their mechanical response is strongly dependent on loading rate and time [13]. The effect of viscoelasticity, which is most observed on nanoindentation, is creep, that is, sinking of the tip into the sample under a constant load [14]. Adhesion between the tip of the nanoindenter and the sample's surface has a big influence on soft materials and can add up to a significant percentage of the overall maximum load [15]. Major sources of difficulty in applying nanoindentation to soft materials also include evaluating the appropriateness of mechanical models [16] and defining proper calibration materials [17]. As the majority of biological materials have water contents up to $80 \%$, it is of paramount importance that nanoindentation tests are carried out in the appropriate medium. It is desirable to perform tests in fluid environment rather than to attempt to infer from measurements on dry (or $50 \%$ relative humidity, $\mathrm{RH}$ ) samples in order to understand their properties and behaviour. To meet this need, the testing capability of the nanomechanical instrument is extended by the development of a fluid cell allowing nanoindentation, nanoscratch, and nanowear testing of samples fully immersed in fluids. This development allows testing under 25-90\% RH. The fluid cell works with the existing pendulum design, and the horizontal loading has several key advantages for testing in fluid [18]. In general, for quantitatively accurate and reproducible results, nanoindentation of soft materials requires further validation and suitable modification. It is necessary to modify the standard testing protocols for stiff materials in order to take into account their viscoelasticity, their roughness and accurately calculate the surface position [19].

In the present study, nanoindentation is used to investigate the nanomechanical behaviour of different soft materials. PDMS, cells and tissues are examined. The nanomechanical properties $(H$ and $E$ ) of PDMS are estimated by the Oliver and Pharr (O\&P) model performed on the unloading data of the load-displacement curves. The influence of poly- mer's viscosity and the effect of loading rate and creep on $H$ and $E$ values of PDMS are also discussed. A classical Hertzian contact analysis is performed in order to obtain values of $E$. Moreover, the nanoscale deformation of PDMS is investigated, and the so-called phenomenon referred in literature as zero load plastic deformation [20] (i.e., the phenomenon during which when the indenter tip is pulled away from the sample, an adhesive attraction deforms the soft polymer along the direction of the tip motion and causes a negative indentation) is evaluated. Adhesion energy at the tip-PDMS surface sample interface is a significantly important parameter and needs to be taken into account for consistent $E$ determination of soft materials by nanoindentation. Finally, the difficulties of the measurement of the nanomechanical properties ( $H$ and $E$ ) of cells and tissues are analyzed showing the need for a modification of the current experimental protocol. Finally, analysis based on the finite element method (FEM) is used to simulate the nanoindentation of PDMS in correlation with experimental data.

\section{Experimental}

2.1. PDMS Sample Preparation. PDMS elastomer sample has been prepared by mixing $30 \mathrm{~g}$ siloxane base with $4.5 \mathrm{~g}$ crosslinking agent. An increase in viscosity is observed during the preparation of the sample. The addition of the crosslinking agent is followed by the addition of catalyst. Its final shape ( $3 \mathrm{~mm}$ thickness with smooth surface at top and rough surface at bottom) is due to the casting process in aluminum pot/pipkin, where the smooth surface is exposed to air and the rough one is in contact with the bottom of the pot (vulcanization time about $24 \mathrm{~h}$ ). The surface of the sample has been cleaned with water prior to testing to avoid contamination [21].

2.2. Instrumentation. The nanoindentation analysis in this work has been performed using a nanomechanical test instrument which allows the application of loads from 1 to $10000 \mu \mathrm{N}$ and the recording of penetration depths as a function of applied loads with a high load resolution $(1 \mathrm{nN})$ and a high displacement resolution. The nanomechanical test instrument employed in this study is equipped with a Scanning Probe Microscope (SPM), in which the sharp probe tip moves in a raster scan pattern across a sample surface using a three-axis piezo positioner. In all depth-sensing tests a total of 10 indents are averaged to determine the mean $E$ values for statistical purposes, with a spacing of $50 \mu \mathrm{m}$ $\left(\sim 45 \% \mathrm{RH}, 23^{\circ} \mathrm{C}\right)$. After the indenter tip makes contact with the specimen surface, the indentation applied load and displacement are recorded simultaneously. Feedback control is performed for its ability to operate under closed loop load or displacement control (this capability provides the means of performing traditional tests utilized for viscoelastic property measurements of biomaterials and polymers, such as creep and stress relaxation tests) [22]. All nanoindentation measurements have been performed with the standard threesided pyramidal Berkovich probe, with an average radius of curvature of about $100 \mathrm{~nm}$. 


\section{Results and Discussion}

\subsection{Polydimethylsiloxane (PDMS)}

3.1.1. Hardness and Elastic Modulus of PDMS. A typical nanoindentation test provides load-displacement data, which are the deformation response of a material. Figure 1 presents typical load-displacement curves, where the applied load is plotted in accordance to the displacement of the indenter. It is obvious that PDMS has a small amount of plastic deformation. The adhesion effect during nanoindentation experiments of soft polymers leads to overestimation of the modulus [2, 23-25]. One effective method to ensure that the zero displacement position is accurately determined is the correct determination of the contact area between the indenter and the sample being tested. One method to define the surface position of soft materials correctly is to perform displacement-controlled experiments as described in Cao et al. [26]. In the present work, the area for the nanoindentation testing was carefully chosen using the SPM, in order to obtain low values of the surface roughness of the sample, that is, $3-4 \mathrm{~nm}$. Thus, it was ensured that no negative load values would appear in the load-displacement curve. The $H$ and $E$ of the PDMS in accordance to the displacement of the tip are presented elsewhere [27], showing the decrease of $H$ and $E$ as the displacement of the tip increased, until they reached a constant value for bulk PDMS. O\&P model [28] was used to estimate the $H$ and $E$ values using the unloading data of the load-displacement curves. The obtained results revealed the heterogeneity of PDMS, that is, the existence of two regions: (1) surface/near surface $\sim 250 \mathrm{~nm}$ thick ( $H \sim$ $10 \mathrm{MPa} \& E \sim 50 \mathrm{MPa})$ and $(2)$ bulk $(H \sim 2 \mathrm{MPa} \&$ $E \sim 8 \mathrm{MPa}$ ) region. Higher $H$ and $E$ values in the surface area are caused probably by higher crosslink density in the low displacement range $(0-300 \mathrm{~nm})$ and the exposure of the PDMS samples in atmospheric air. Several studies on PDMS samples via nanoindentation have revealed various nanomechanical properties [29-34]. Hou et al. [30] investigated PDMS samples (surface $E=19 \mathrm{MPa}$, bulk region $E=$ $8 \mathrm{MPa}$ ) with average surface roughness $\sim 15 \mathrm{~nm}$. Greenwood et al. [33] confirmed the increase in $E$ of PDMS with higher crosslinking agent concentrations due to polymerization degree decrease $(E=8.7 \mathrm{MPa})$.

3.1.2. Time-Dependent Behaviour of PDMS. The mechanical behaviour of polymers is usually described by viscoelastic and/or viscoplastic characteristics, depending on time (or frequency) as well as temperature, which makes the mechanical response of the polymer systems complicated. An analysis of the extension load-displacement curves reveals the viscoelastic relaxation processes in the bulk polymer that causes the monotonic rate dependence of the adhesioninduced indentation. The viscoelastic relaxation processes in the bulk polymer have different components based on the molecular weight between crosslinks. An analysis of the retraction load-displacement curves shows that besides the viscoelastic processes in the bulk, relaxation processes also occur at the interface of the tip-polymer surface. Consideration of the adhesion energy at the interface of the tip-PDMS

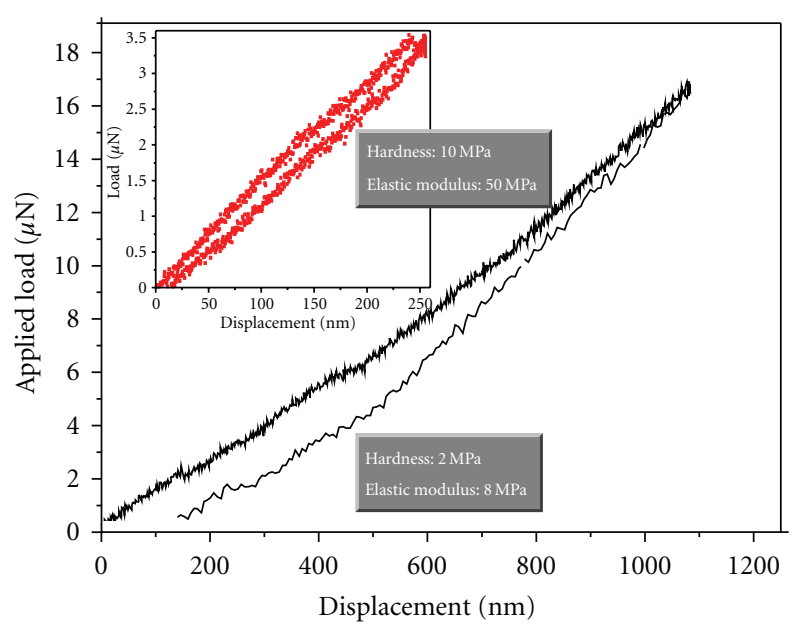

Figure 1: Typical plots of load against the displacement of the indenter for PDMS.

surface is a significantly important parameter and needs to be taken into account for consistent $E$ determination of soft materials by nanoindentation.

When materials are subjected to a constant applied load for a period of time (hold time), creep (a time-dependent deformation) is observed. Creep is an important phenomenon which describes viscoelasticity of polymers. A better understanding of creep would clearly improve the ability to enhance the service performance of polymers. In the present work, the effect of loading rate and creep on $H$ and $E$ is studied.

(1) Loading Rate. Regarding the influence of polymer's viscosity $[35,36]$, the effect of loading rate on $H$ and $E$ of PDMS is investigated. The effect of loading rate on $H$ and $E$ values is studied for loading rates $0.1 \mu \mathrm{N} / \mathrm{s}, 0.8 \mu \mathrm{N} / \mathrm{s}$, $1.2 \mu \mathrm{N} / \mathrm{s}, 1.5 \mu \mathrm{N} / \mathrm{s}$, and $8 \mu \mathrm{N} / \mathrm{s}$ in PDMS with a maximum load of $500 \mu \mathrm{N}$ through a three-segment process (hold time $3 \mathrm{~s}$ between load and unload segments). $H$ and $E$ values are relatively high (3.3 and 9.8 MPa, resp.) for a loading rate of $0.1 \mu \mathrm{N} / \mathrm{s}$, then decreasing with the increase of loading rate and reaching constant values ( $\sim 2$ and $5.6 \mathrm{MPa}$, resp.). The unloading rate is the same with that of loading in each case. The $H$ and $E$ values have been estimated by O\&P model [28] and are presented in Table $1 . H$ and $E$ values versus loadingunloading rate are presented in Figure 2.

Since the same force profile is applied during a longer time interval at low loading-unloading rates than that of high loading-unloading rates, a larger amount of kinetic energy is applied to the PDMS at low loading rate than that at high loading rate, resulting in differences in nanomechanical properties because of the time-dependent viscoelastic behaviour of PDMS. This is because in case of PDMS, which is a viscoelastic material whose glass transition temperature is far below room temperature, when the push-in rate is low, the PDMS molecules are able to move (deformation and subsequent recovery to their equilibrium conformation) in response to the applied deformation. The mechanical 
TABLe 1: $H$ and $E$ values estimated by Oliver-Pharr model [28].

\begin{tabular}{lll}
\hline Loading-unloading rate $(\mu \mathrm{N} / \mathrm{s})$ & $H(\mathrm{MPa})$ & $E(\mathrm{MPa})$ \\
\hline 0.1 & $3.3 \pm 0.2$ & $9.8 \pm 0.5$ \\
0.8 & $2.2 \pm 0.1$ & $6.3 \pm 0.3$ \\
1.2 & $2.2 \pm 0.1$ & $6.2 \pm 0.3$ \\
1.5 & $2.4 \pm 0.1$ & $6.2 \pm 0.3$ \\
8.0 & $1.9 \pm 0.1$ & $5.6 \pm 0.3$ \\
\hline
\end{tabular}

response of elastomers under applied loading is one of the major issues in many applications such as tunable microdoublet lenses [37] and dielectric elastomer actuators [38].

(2) Creep. One of the commonly used techniques taking into account the viscoelastic properties of polymeric materials during nanoindentation is to hold the indenter at the maximum load, for a period of time [39]. This, however, leads to creep effects during indentation, in which the measured $H$ and $E$ are dependent to the hold period, maximum load and loading/unloading rates [40]. The term creep is often used to describe a delayed response to an applied stress or strain that may be a result of viscoelastic or viscoplastic deformation [41]. Nevertheless, creep influences the maximum displacement and the unloading curve in a way that nonnegligible errors of $H$ and $E$ calculations may occur [42]. In the present study, the nanoindentation creep behaviour of PDMS is investigated. Different hold rates are selected, and the nanomechanical properties $(H$ and $E)$ are calculated. In Figure 3, $H$ and $E$ values as a function of hold period are presented.

From Figure 3, it is obvious that $H$ and $E$ values decrease as the hold period increases, until they reach almost constant values ( $\sim 0.5 \mathrm{MPa}$ and $\sim 1.9 \mathrm{MPa}$, resp.).

3.1.3. Contact Analysis and Zero Load Plastic Deformation. A classical Hertzian contact analysis is performed in order to calculate the $E$. $E$ value is $\sim 70 \mathrm{MPa}$, which is lower than that obtained from the O\&P method (130 MPa). This difference is due to the assumption given in the Hertz formulation stating that the contact depth $\left(h_{c}\right)$ is related to the total penetration depth $(h), h=2 h_{c}$. Only for ideal elastic contact $\left(h=2 h_{c}\right)$, both analysis will compute the same moduli. The classical Hertzian model is a hard contact model that does not take adhesive interactions into account. Moreover, the plastic deformation when no load is applied to PDMS is examined in the present work. The dynamic load signal (dynamic contact stiffness) is used to provide much greater sensitivity to surface contact and surface stiffness in comparison with a change in quasistatic force or stiffness measurement. The dynamic load signal as the tip approaches the surface, snaps into contact because of surface forces, and measures the increase in the surface stiffness with displacement [30]. Figure 4 presents the applied load versus displacement into PDMS surface [43]. Although no load had been applied to the sample, there is an interaction between the tip and the sample. This phenomenon is frequently referred in the

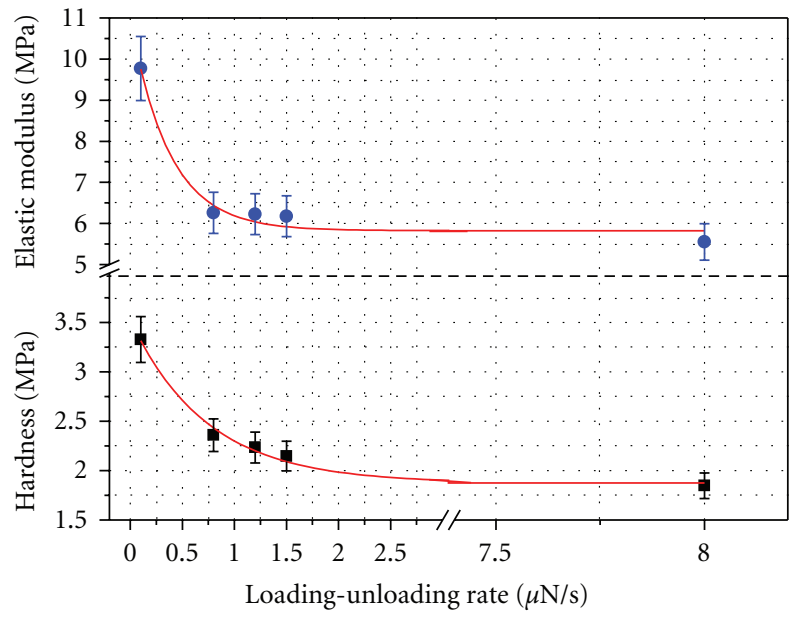

Figure 2: $H$ and $E$ values for different loading rates.

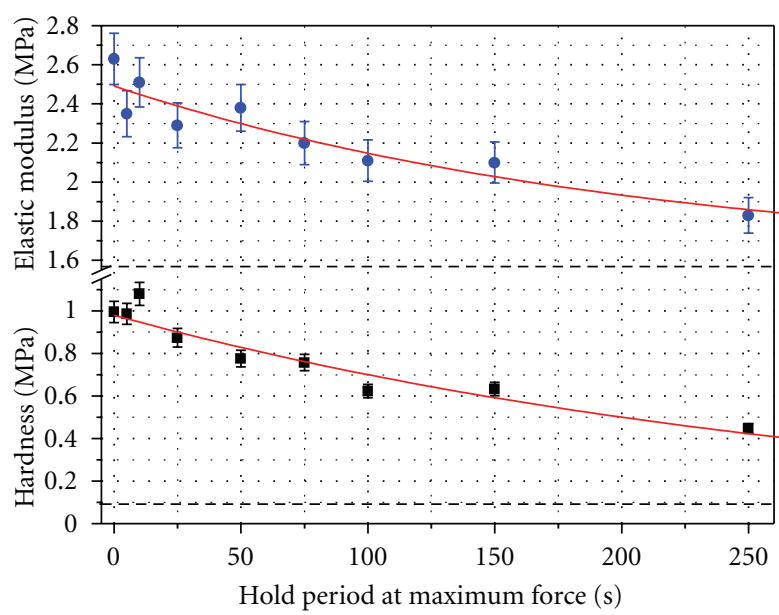

Figure 3: $H$ and $E$ values as a function of hold period at maximum force for PDMS.

literature as zero load plastic deformation (ZLPD) [20]. The point where the interaction becomes attractive is the point where the tip contacts the surface. From Figure 4, one can see that when the tip is pulled away from the sample, the adhesive attraction deforms the soft polymer along the direction of the tip motion and causes a negative indentation (i.e., polymer extension in a typical tensile stress test). At point " 0 ," where the tip is attracted to the sample surface because of the adhesive interaction, the stored elastic energy and the surface energy are balanced. Indentation between the point where the tip starts to contact the sample surface and point " 0 " is defined as the adhesion-induced indentation, while point " 1 " corresponds to the adherence force.

In many dynamic adhesion processes, it is found that more energy is required to separate two surfaces in adhesive contact in relation to the energy that is released when they come into contact. This is usually manifested as a hysteresis between the loading and unloading force versus separation force curves in a force measurement. The adhesion hysteresis is widely believed to be due to energy dissipation in the bulk 


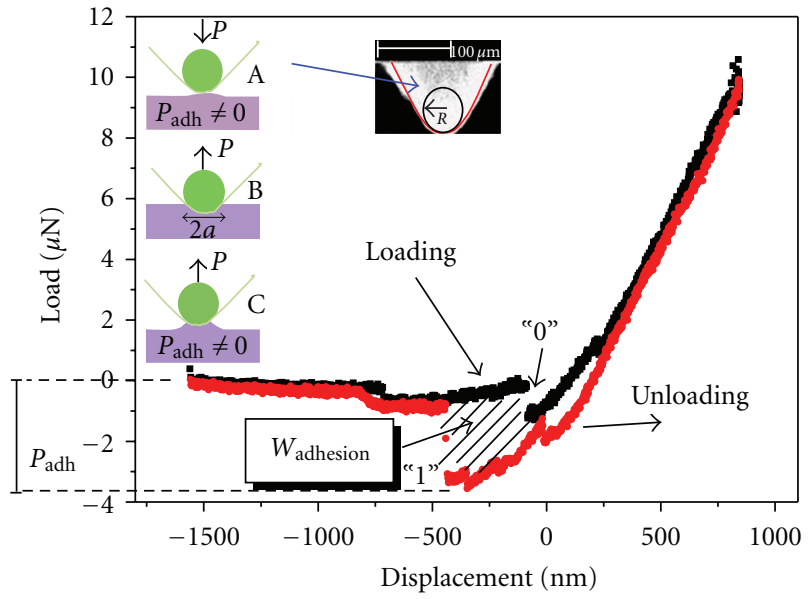

Figure 4: Load versus displacement as the tip approaches the surface, snaps into contact because of surface forces in the surface of PDMS.

material and at the crack tip. A number of mechanisms have been proposed to explain the adhesion hysteresis. For instance, adhesion hysteresis is influenced by viscoelastic or plastic bulk deformation, the formation of weak or strong dipolar attractions at the interface, and crosslinking or physical entangling of tethered chains across the interface; these mechanisms are usually coupled in a practical adhesion system. Considerable work has been performed in order to investigate the different mechanisms for the adhesion hysteresis qualitatively or quantitatively. Silberzan et al. [44], Choi et al. [45-47], Kim et al. [48], Mason et al. [49], and Perutz et al. $[50,51]$ studied the adhesion hysteresis of PDMSPDMS self-adhesion systems and PDMS self-assembled monolayer systems using the macroscopic Johnson-KendallRoberts (JKR) method. In these experiments, the polymer crosslink density, sol fraction, surface functionality, loading and unloading rates, and dwell time of contact were varied. The contributions to the adhesion hysteresis from the viscoelasticity of the bulk material were ignored, because the loading and unloading processes were controlled to follow a quasiequilibrium process. Instead, adhesion hysteresis was found to be dominated by hydrogen bonds, crosslinking, and physical chain entanglements. Pickering and Vancso [52], Vakarelski et al. [53], Noël et al. [54], and Gillies et al. [55] used AFM to study the adhesion hysteresis of polymer systems and found that the viscoelasticity was the dominant factor.

The energy which has to be overcome is the energ required to bend the cantilever until it reaches the value of adhesion force $\left(F_{\mathrm{ad}}\right)$. The Derjaguin-Muller-Toporov (DMT) [56] and the JKR [57] theories establish a relationship between the adhesion force $\left(F_{\text {adh }}\right)$, the Berkovich-PDMS interaction constant $(k)$, and the thermodynamic work of adhesion ( $\left.W_{\text {adh }}\right)$, given by

$$
F_{\text {adh }}=-k W_{\text {adh }} .
$$

The dependence of $F_{\text {adh }}$ on the $W_{\text {adh }}$ is presented in Figure 5. This dependence of $F_{\mathrm{ad}}$ on the $W_{\mathrm{ad}}$ is in good

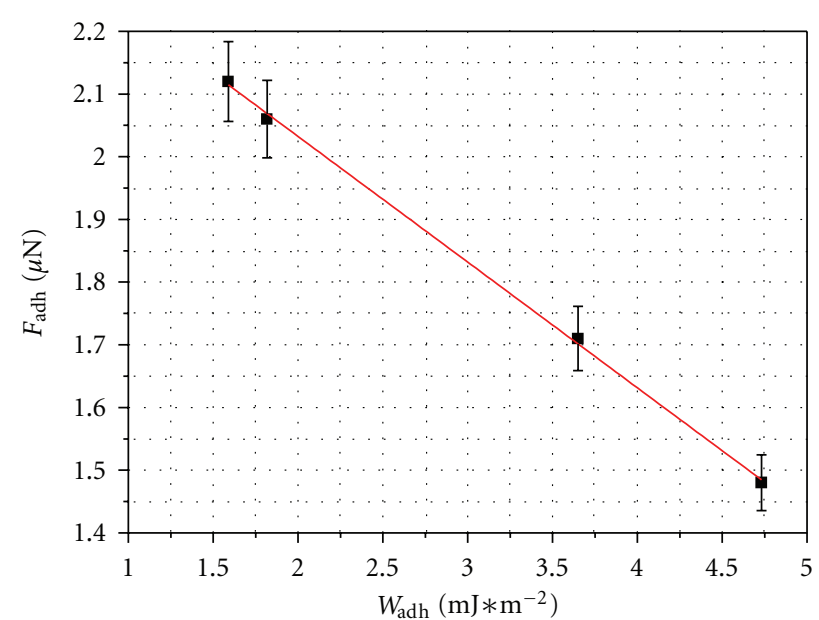

FIGURE 5: Work of adhesion calculated through (1) for various $F_{\text {ad }}$, with a slope of -0.2 (this work).

agreement with findings of other researchers $[1,6,58,59]$. Song et al. [58] performed indentations to untreated and UV-treated PDMS and compared the obtained $F_{\text {ad }}$ values (43.1 and $1.7 \mathrm{nN}$, resp.). Similar studies revealed dependence on the hydrophobicity of the PDMS surface $\left(F_{\mathrm{ad}} \sim 60 \mathrm{nN}[6\right.$, 59]) and the crosslinking density ( $F_{\text {ad }}$ from 93.1 to $43.6 \mu \mathrm{N}$ with decreasing crosslinker concentration [1]).

Approaching and retracting parts of force curves are often not identical due to various reasons (in liquids hydrodynamic drag on the cantilever is one of the reasons) [60]. It causes a difference in the zero force line. In order to prevent a jump-in, contact the use of stiffer cantilevers is proposed (however sensitivity is lost). Due to this fact, alternative techniques have been performed to access the unstable regime such as the application of a force feedback (electric or magnetic) to balance the surface force [61-67], kinetic force experiments $[68,69]$, and using a microsphere rather than a microfabricated tip (the hydrodynamic drag can be used to compensate for the attraction) [60]. Another instability occurs when tip or sample surface is not perfectly rigid but is deformed by the tip. For that case of elastic deformation, Pethica and Sutton showed that at sufficiently small separations, typically 1-2 $\AA$, the tip and the sample will jump together, irrespective of apparatus construction [70]. A similar jump occurs for nonelastic deformations. In this case, however, the jump depends on the rate of the plastic deformation [71]. When retracting the tip adhesion often keeps it in contact with the surface until the cantilever force overcomes $F_{\text {ad }}$. This even happens in purely elastic, nondissipative situations. Another issue is the influence of interfacial adhesive forces on the indentation contact area determination. The limitations in using nanoindentation for quantitatively determining the PDMS properties are uncertainties associated with the initial tip-sample contact point and tip shape at large depths. Gupta et al. [72] investigated the effects of adhesion on the $E$ for soft PDMS samples, including the adhesive forces to the analysis of the nanoindentation data in order to elucidate the apparent linearity of 
the load-displacement curves with the differences in $E$ values obtained from Hertzian model observed at the different applied loads (applied loads from 5 to $20 \mu \mathrm{N}, E$ values from $\sim 1.8$ to $1.4 \mathrm{MPa}$, resp.). Carrillo et al. [2] performed adhesion experiments in aqueous solution in order to study the influence of experimental environment on the adhesion work. Their results indicated a significant decrease in the adhesive force when testing was performed in distilled water. Since the contribution of electrostatic attraction to the total adhesive force is relatively large for PDMS (in addition to the dispersive interactions due to the nonpolar behavior of PDMS), the decrease found in the measured $F_{\mathrm{ad}}$ is probably the result of the weakening of the electrostatic charge under wet conditions. Moreover, the $F_{\text {ad }}$ values do not seem to be converging to zero (repellant interaction of PDMS (an inherent hydrophobic material mainly due to the presence of $-\mathrm{CH}_{3}$ groups) with water, and constant presence of the dispersive van der Waals forces). Thus, the current calculation methods, though seemingly adequate for adhesive polymeric materials, need proper modification of the current experimental protocol in order to capture the dynamic response of materials for which viscous or rubbery flow conditions exist (i.e., where energy loss is a more significant factor) and the adhesion tip-sample interactions [73].

3.2. Cells and Tissues. The mechanical characterization of tissues and other biological materials is of outmost importance in clinical medicine and the field of biomaterials. Soft hydrated materials, such as vascular tissues and other biomaterials, are a challenging class of materials as they are composed of hierarchical structures with important features down to the nanometer or micrometer scale. Because of its small probe size, nanoindentation can be used to measure local material properties and deformation in small, thin, and heterogeneous samples. This allows testing of tissue specimens that are unsuitable for traditional mechanical testing, including biopsy specimens. Nanoindentation is also useful for measuring mechanical properties or microstructural features within bulk samples, characterizing the properties of individual constituents within composite or heterogeneous samples, or mapping mechanical properties across a sample surface. As a result, nanoindentation is emerging as a valuable mechanical testing technique for cells and tissues [14].

Because of the considerable differences in the mechanical responses when compared to hard solids, different testing and analysis protocols must be performed for the extraction of meaningful indentation data from soft biological specimens. The goal to make indentation testing of soft biological tissues more reproducible and also capable of evaluating the effects of changes in fine structure on tissues stiffnessboth mean values and site-to-site variability-will result in a new protocol for preparing and mechanically testing tissues and cells in a mode that maintains their bona fide structure and their biological functioning. Some commonly used indentation testing protocols include the use of preloads before loading and/or long hold periods before unloading to reduce time-dependent effects on the resulting data. However, preloading of soft biological tissues would inevitably move the water within the tissue. Inherent in the analyses of tissues and cells, is the need to precisely locate the initial point of contact between the tip and the specimen surface [74]. For soft biological tissues, the accurate determination was described by A-Hassan et al. [75] to be "one of the most vexing problems."

There is currently no well-accepted technique for viscoelastic or poroelastic analysis of indentation data in soft hydrated materials, a deficiency that makes the quantitative values measured through this technique unreliable [14]. By using the combination of hydration system, proper tip geometry, and control material, this limitation can be addressed, broadening the applicability of nanoindentation in the study of diverse biomaterials. Tip selection is also a critical issue in the indentation of soft materials. For commonly used indentation of hard materials, the Berkovich tip and the cube-corner tip, three-sided pyramidal tips that come to a sharp point, are commonly used. This tip geometry has also been used in the mechanical testing of mineralized tissues and many glassy polymers [76-78]. However, spherical tips are commonly used when indenting soft polymers [23, 7981]. This geometry leads to a larger contact area and hence a larger contact stiffness at the surface. Additionally, the lack of sharp edges minimizes plastic deformation and stress concentrations in the indented material [81-85]. A third option on occasion utilized in the study of viscoelastic materials is the flat punch $[79,86,87]$. The flat tip has the characteristic of having a constant, known contact area as a function of depth. However, for this contact area to be valid full contact is required with the surface, and thus the flat punch is optimal only for very flat surfaces or deep depths, while spherical tips will contact the surface with an orb shape even if there is a slight tilt to the sample or small amounts of surface roughness. In Figure 6 [14], a comparison of contact sizes of different types of tips during indentation is made.

The full assessment of mechanical properties of cells and tissues is limited by the complex nature of their structure and physiological environment. Hydration is a major issue for biological materials, since most of them are $80 \%$ water based. Attempts of measuring the nanomechanical properties of an endometrial tissue have been made, but there were no successful results since the sample was destroyed before the end of the measurement due to lack of hydration.

A liquid tip has been recently introduced in order to perform tests at in vitro conditions. The liquid tip allows a liquid film of up to $3 \mathrm{~mm}$ thick on the sample surface (Figure 7 ), [88, 89]. The longer shaft of the liquid tip allows machine calibrations in the testing media and changes in damping behaviour. Testing in liquids also causes meniscus forces on the indenter. Therefore it is important for the indenter to be fully submerged in the liquid prior to testing. A minimization of the deformation caused by the surface approach and detection is achieved by using a two-step approach. In the first step a high setpoint is used to penetrate the liquid. The deformation before the actual indent is reduced by using a lower contact force in the second step [13]. 


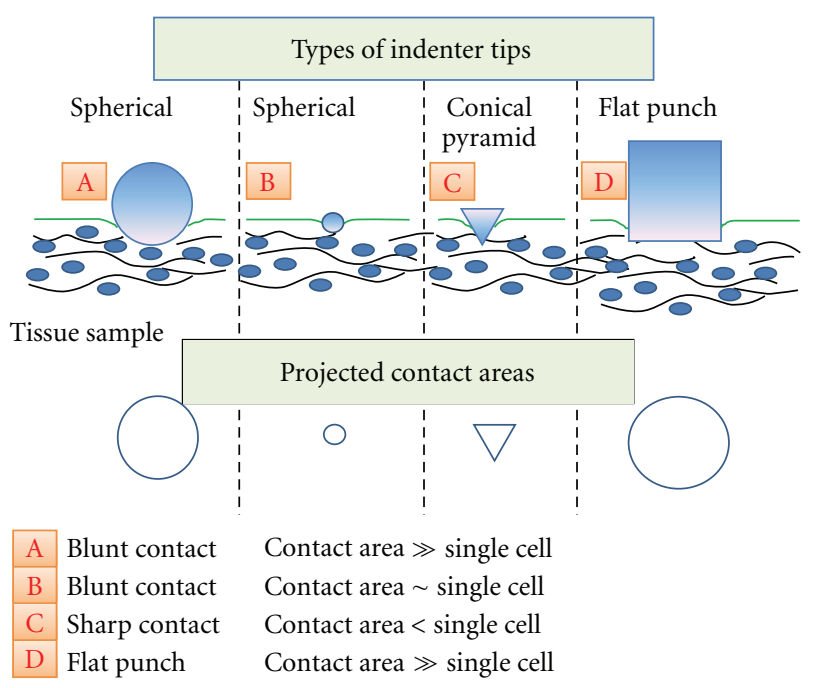

FIGURE 6: Schematical draw illustrating tip selection for indentation of a tissue sample. Comparison of contact sizes during indentation using (A) a large diameter spherical tip, (B) a small diameter spherical tip, (C) a Berkovich tip, and (D) a cylindrical flat punch [14].

Akhtar et al. [90] used the nanoindentation technique to determine trabecular stiffness of bovine bone, both dehydrated and rehydrated. Testing was conducted using a customized liquid cell. Values of $E$ were obtained for dehydrated and rehydrated trabeculae (18.3 $\mathrm{GPa}$ and $14.3 \mathrm{GPa}$, resp.). Hence, dehydration led to an increase of approximately $22 \%$ in $E$.

Rico et al. [91] developed a contact model of a blunted pyramidal tip and assessed the suitability of pyramidal tips for probing mechanical properties of soft gels and living cells (blunted pyramidal tip indenting an elastic halfspace). The measurement of $E$ and complex shear modulus $G^{*}=G^{\prime}+i G^{\prime \prime}$ of agarose gels and A549 alveolar epithelial cells with pyramidal tips and the comparison with those obtained with spherical tips led to the conclusion that the gels exhibited an elastic behaviour with almost coincident loading and unloading force curves and negligible values of $G^{\prime}$. E fell sharply with indentation up to $\sim 300 \mathrm{~nm}$, showing a linear regime for deeper indentations. A similar indentation dependence of $E$ with twofold lower values at the linear regime was obtained with the spherical tip fitted (Hertz's model fit). The dependence of $E$ on indentation in cells was parallel to that found in gels. Cells exhibited viscoelastic behaviour with $G^{\prime \prime} / G^{\prime}$ ratio $\sim 1 / 4$. In Figure 8 , the scanning electron micrographs of pyramidal and spherical tips used in agarose gels are presented.

Daphalapurkar et al. [92] used nanoindentation techniques to measure the viscoelastic functions of four quadrants of human tympanic membrane (TM). TM (or eardrum) is composed of three membrane layers with collagen fibers oriented in the radial and circumferential directions and exhibits viscoelastic behaviour with membrane (or inplane) properties different from through-thickness (or outof-plane) properties. Due to the interaction of bundled fibers and ground substance, which is inhomogeneous, these properties could vary with locations. For measurement of in-plane Young's relaxation modulus, a sectioned quadrant of the TM on a circular hole was fixed, and a spherical nanoindenter tip was used to apply load at the center of the suspended circular portion of the specimen. An inverse problem-solving methodology was employed using finite element analysis to determine the average in-plane Young's relaxation modulus of the TM quadrant. Results indicated that the in-plane steady-state Young's relaxation modulus for four quadrants of the TM did not change significantly. However, a variation of the modulus from $25.7 \mathrm{MPa}$ to 37.8 MPa was observed with measurements from different individuals. For measurement of Young's relaxation modulus in the through-thickness direction a spherical indenter tip was used to indent into different locations on the surface of the TM specimen supported by a substrate. Viscoelastic contact mechanics analysis of the load-displacement data, representative primarily of the through-thickness stiffness of the TM, was conducted to extract the Young's relaxation modulus in the out-of-plane direction. Results indicate a wide range of steady-state Young's relaxation modulus values, from $2 \mathrm{MPa}$ to $15 \mathrm{MPa}$, in the through-thickness direction over the TM.

Zysset et al. [76] performed nanoindentation experiments on wet bone tissue. A total of 39 indentations failed probably due to the invasion of water on the surface of the tissue and were attributed to zero values for both $H$ and $E$. From the remaining indentations, the $E$ ranged from $6.9 \pm 4.3 \mathrm{GPa}$ in trabecular tissue from the femoral neck of a 74-yr-old female up to $25.0 \pm 4.3 \mathrm{GPa}$ in interstitial tissue from the diaphyseal cortex of a 69 -yr-old female. $H$ followed a similar distribution as $E$, but with lower statistical contrast.

In Figure 9, typical load-displacement curves of cortical and trabecular bone are presented indicating a different response of cortical and trabecular tissue.

Nanoindentation has the ability to detect changes in mechanical properties associated with small defects of the tissue. Considerable research relating to the links between the biomechanical properties of cells and human diseases has been carried out [7-11]. Nanoindentation can be used to compare the bone tissue properties in healthy bones with those of diseased and genetically modified ones. Both studies aid in understanding the role of local tissue properties and hierarchical structure in macroscale fracture and deformation mechanisms of bone [14]. Figure 10 presents the mapping of the $E$ through a cartilage defect in a rabbit knee joint using nanoindentation. It is obvious that $E$ values of healthy and diseased regions of the cartilage are different. Mechanical parameters in specific regions of rabbit finger joint cartilage can be associated with structural parameters such as cell density and thickness of the superficial zone [14].

In conclusion, nanoindentation technique has recently emerged as a powerful tool for measuring nanomechanical properties of cells and tissues. It can play a valuable role in the assessment of material properties of healthy, diseased, and tissue-engineered soft tissues. Because of the differences in the mechanical responses compared to hard solids, different analysis protocols should be used to extract 


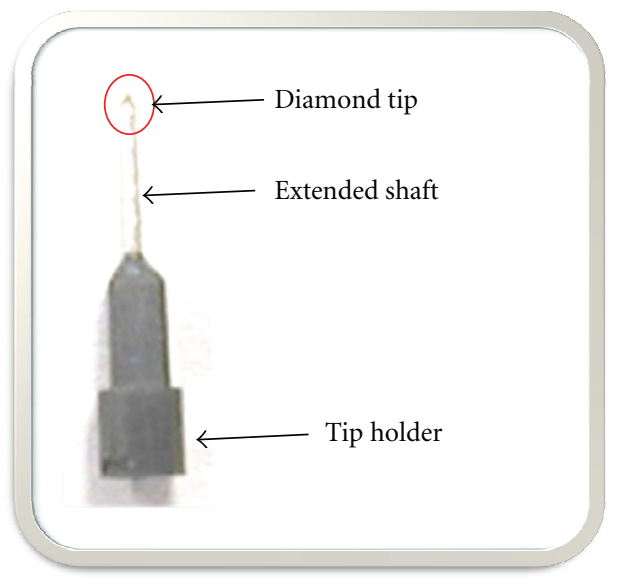

(a)

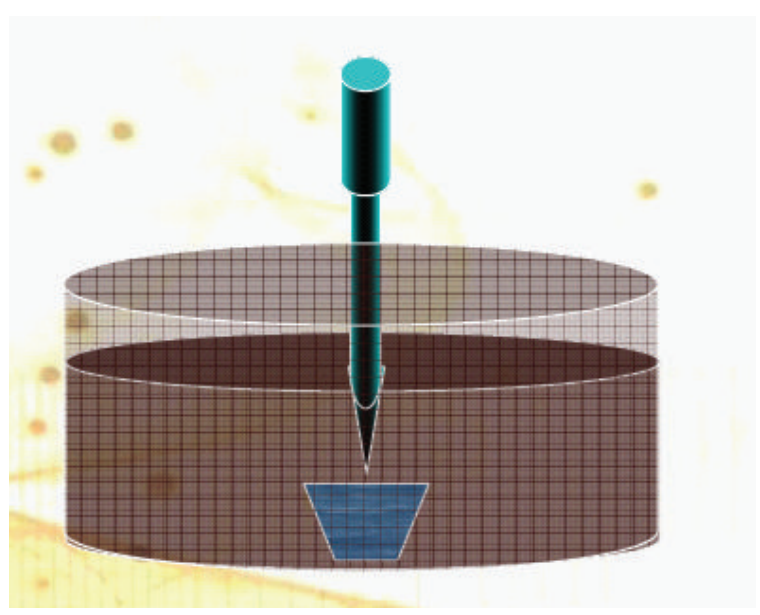

(b)

FIGURE 7: Schematic of fluid tip showing extended shaft for reduced meniscus force during testing [88, 89].

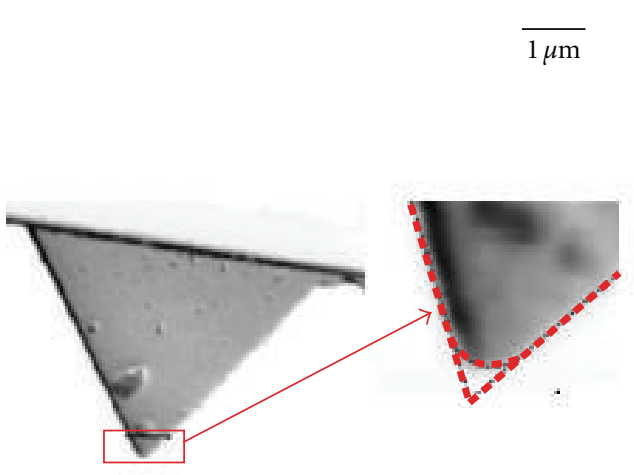

(a)

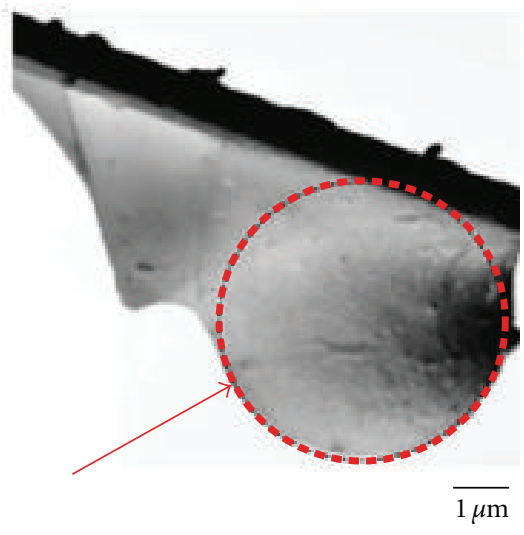

(b)

FIGURE 8: Scanning electron micrographs of (a) pyramidal and (b) spherical tips used in agarose gels (bar $=1 \mu \mathrm{m})$, where the spherical shape is noted in circle. The inset shows the blunted pyramidal approximation (bar $=100 \mathrm{~nm})$ [91].

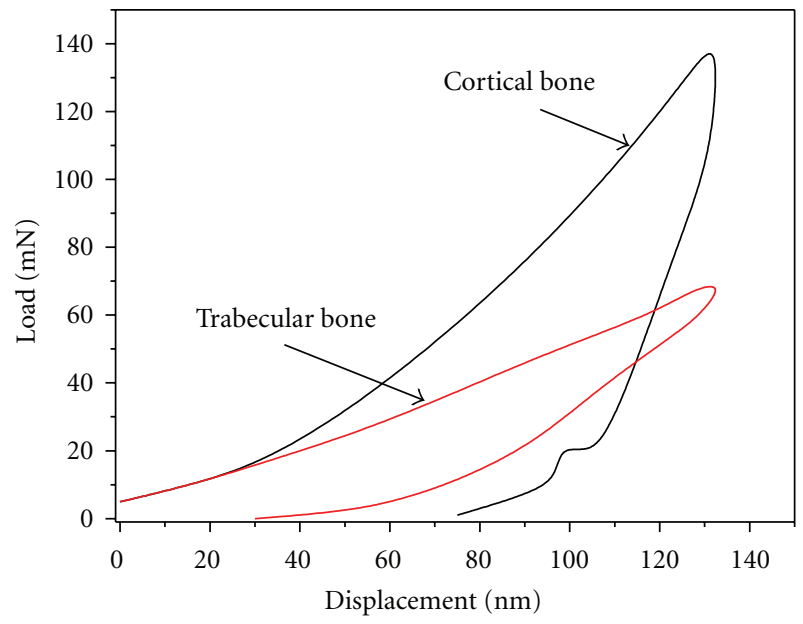

Figure 9: Typical load-displacement curves obtained by indentation of cortical and trabecular bone.

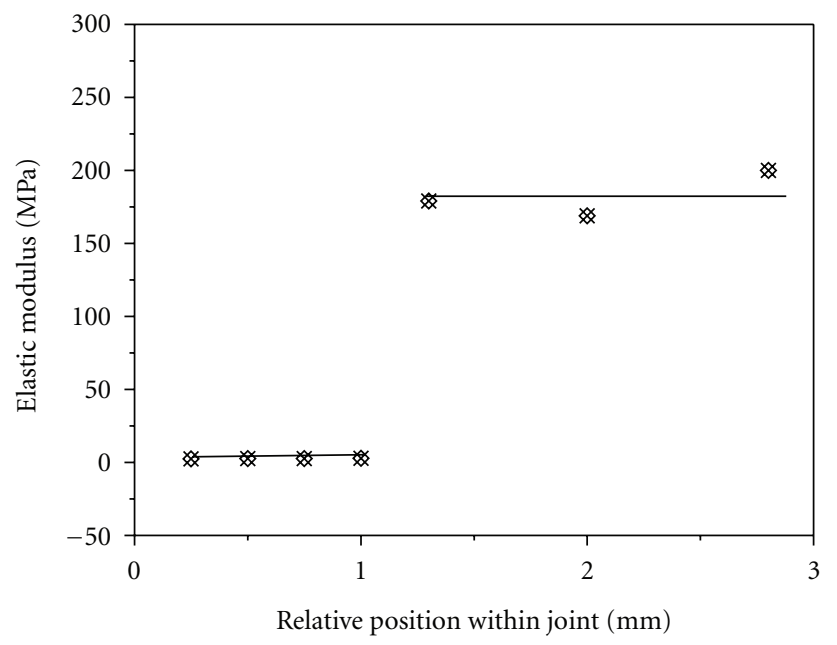

FIgURE 10: Mapping of a cartilage defect in a rabbit knee joint. 


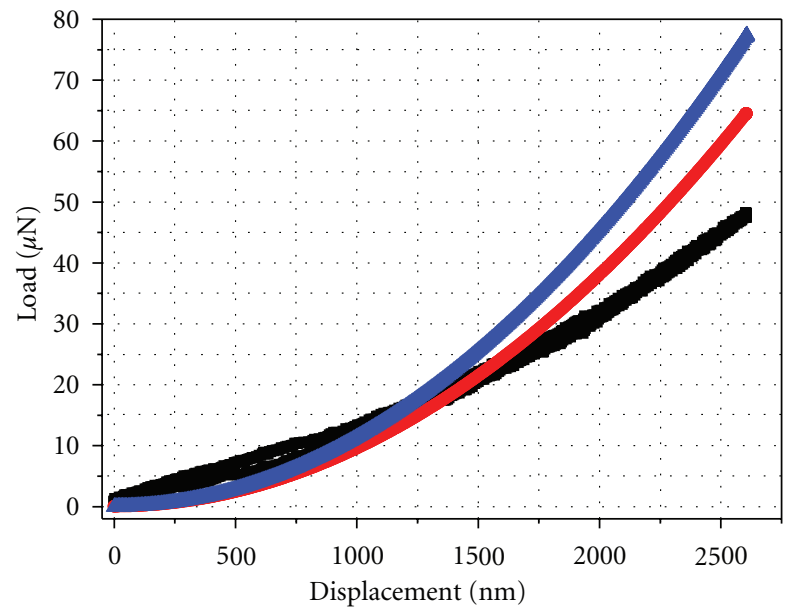

- Experiment

- Analytical solution

A FEM

FIGURE 11: Load-displacement obtained through nanoindentation experiment (black curve), Sneddon's analytical solution (red curve) and FEM analysis (blue curve) [101].

meaningful indentation data from biological specimens and make indentation testing more reproducible. Recently, heating/cooling stages have been introduced. Heating/cooling stages allow the whole range of soft matter phase behaviours to be explored with SPM. Several approaches have been taken [93-96], either using peltier devices (which are easy to implement) or resistive heaters (which provide greater temperature range), and heater/coolers are now available for most commercial instruments [97].

\subsection{Finite Element Modeling of Nanoindentation of Soft Mat-} ter. Sharp indentation of soft matter is widely investigated numerically using the finite element method. Large deformation theory is relied upon for accuracy. In recent studies, cone and Vickers indentation is considered, and in particular the study focuses on second-order effects on relevant indentation quantities in the microindentation regime. The secondorder effects include indenter tip radius, friction, in general, effects due to different values on the included angle of the cone indenter, showing that frictional effects as well as effects due to indenter tip roundness are small at cone indentation but friction can substantially influence the results in case of Vickers indentation (most likely due to frictional effects at the edges of the indenter); such behaviour is not accurately described using conventional theory of friction, so in a recent work a numerical approach for this purpose is discussed [98]. Lim and Chaudhri $[99,100]$ performed careful and comprehensive experimental investigations; five highly elastic polymers and rubber materials were indented by cone and Vickers (sharp pyramid indenter with a quadratic base) indenters, and the main conclusion was that deviations between theory and experiments existed in case of Vickers indentation. This is certainly an alarming result taking into account that existing equations form the basis for many

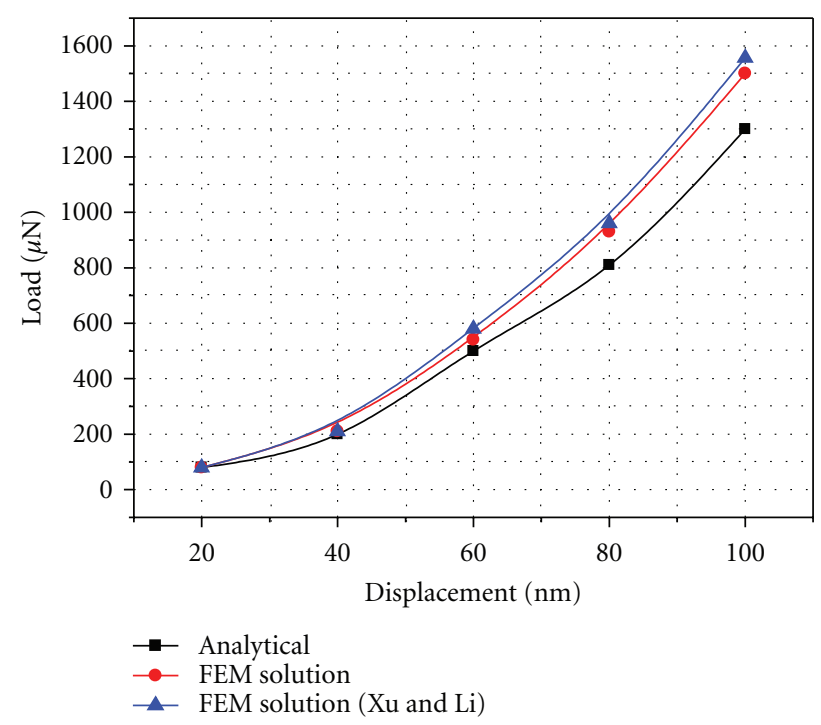

Figure 12: Cone indentation $\left(\alpha=140.6^{\circ}\right)$ —comparison between present FEM results, FEM results by Xu and Li [104], and analytical results by Sneddon according to (2).

standard formulae designed for material characterization using indentation. There are many possible explanations for this discrepancy such as friction, remote boundary effects, contained plastic deformation, and tip radius effects. It is suggested that frictional effects at the edges of the Vickers indenter might contribute, but it could be argued that at elastic indentation, for example, tip roundness effects are of importance. It is the purpose of the present paper to investigate this important issue further.

The nanoindentation of soft matter (PDMS in this work) is simulated with FEM analysis [101] using ANSYS [102], and the load-displacement curve through this analysis is obtained and compared with the analytical solution provided by Sneddon's relationship

$$
P=\frac{2 E h^{2} \tan (a / 2)}{\pi\left(1-v^{2}\right)} .
$$

The three curves are presented in Figure 11 (experimental load-displacement curve for $50 \mu \mathrm{N}$ of applied load and $2500 \mathrm{~nm}$ of displacement). It is obvious that the FEM analysis curve and the curve based on Sneddon's analysis are in good agreement with the experimental curve (Figures 11 and 12). Sneddon's solution assumes that the indenter is perfectly sharp and rigid. Frictional effects are not included in these analyses. For displacements lower than $\sim 1250 \mathrm{~nm}$, the three curves are almost identical. Small deviations are observed due to the fact that the indenter tip is never perfectly sharp. For displacements higher than $\sim 1250 \mathrm{~nm}$, the simulated curves deviate from the experimental one. FEM analysis results are higher due to large deformation effects. This phenomenon has also been reported by Kamran and Larsson [98] and $\mathrm{Xu}$ and $\mathrm{Li}$ [103] in similar experiments.

In further investigation, a quantitative analysis of the problem will be conducted, and then nonlocal frictional 
models have to be implemented into the numerical scheme. In commercial finite element packages, this can be achieved by using a so-called "elastic slip" description, compare or confer for example ABAQUS [104]. In the "elastic slip" description the Coulomb condition is not applied pointwise but weighted over an area region with a so-called mollifying function, Zhong [105]. Specifically, the characteristic length of the area region then constitutes the length scale in the indentation problem. It should be mentioned that the present results, although first and foremost intended for an investigation of sharp elastic indentation problems, are relevant also for other types of contact problems. Typically, such problems would include for example nanoindentation methods for determination of the elastic stiffness of elastoplastic materials $[28,98-100]$ and scratching of polymers [106-109].

\section{Conclusions}

In the present study, nanoscale deformation and nanomechanical properties of polydimethylsiloxane, cells and tissues are presented. More specifically,

(i) the nanomechanical properties ( $H$ and $E$ ) of PDMS were estimated with the Oliver and Pharr (O\&P) model and determined the heterogeneity of PDMS, namely: a surface/near surface region, $\sim 250 \mathrm{~nm}$ thick $(H \sim 10 \mathrm{MPa} \& E \sim 50 \mathrm{MPa})$, and a bulk region $(H \sim 2 \mathrm{MPa} \& E \sim 8 \mathrm{MPa})$. The surface/near surface region with enhanced nanomechanical properties was attributed to exposure of the samples to atmospheric air and higher concentration of the crosslinking agent in the surface;

(ii) a number of problems arise with the application of nanoindentation technique to polymeric materials. In general, $E$ tends to increase with decreasing penetration depth, often referred to as an indentation size effect. Comparisons of modulus values are most appropriate for polymer samples with identical chemistry, molecular weight, and processing history, because quoted values of $E$ for many polymer systems can cover a large range due to potential variations in microstructure, semicrystalline morphology, anisotropy, molecular weight, crosslink density, and so forth;

(iii) the time-dependent behaviour of PDMS was examined. The influence of polymer's viscosity and the effect of loading rate and creep on $H$ and $E$ values of PDMS were studied and should be taken into account. From the creep measurements on PDMS, $H$ and $E$ were found to decrease as the hold time increased, until they reached a constant value for bulk PDMS. The analysis of ZLPD of PDMS revealed that after the indenter tip was pulled away from the sample, the adhesive attraction deformed the soft polymer along the direction of the tip motion and caused a negative indentation (for applied load $\sim 4.5 \mu \mathrm{N})$. Thus, consideration of the adhesion energy at the tip-sample interface is requisite for determining accurate $E$ of PDMS samples and other soft, elastomeric materials from nanoindentation experiments, since soft material samples are expected to have significant adhesive forces;

(iv) the nanomechanical properties ( $H$ and $E$ ) of cells and tissues were reviewed revealing the need for a modification of the current experimental protocol. As soft tissues have water contents up to $80 \%$, it is important that tests are carried out in the appropriate medium. For this reason, a liquid tip can be used, which allows a liquid film of up to $3 \mathrm{~mm}$ on the sample surface. Considering the hydration system, proper tip geometry, testing protocols and improved analysis methods, and calibration materials (with similar properties to the probed materials) could broaden the applicability of nanoindentation in the quantitative assessment of mechanical behaviour of materials that were previously unattainable, such as cells and tissues;

(v) load-displacement curve from FEM analysis is compared with the experimental data; the one based on Sneddon's relationship showing that the results are in good correlation for lower than $\sim 1250 \mathrm{~nm}$ displacements. For higher displacements, the FEM analysis results are higher due to large deformation effects of PDMS.

While new techniques for conventional nanoindentation continue to evolve, scientists are investigating the system's ability to measure force in the nanonewton range in order to quantify molecular binding interactions. Binding forces can also be quantified when a small number of molecular interactions occur, providing piconewton binding measurements for individual molecular pairs. There are many exciting possibilities for scanning probe microscopy and nanoindentation providing convenience and flexibility at the nanoscale.

\section{Acknowledgment}

The author wishes to acknowledge Ms. V. P. Tsikourkitoudi, Mr. E. P. Koumoulos, and Mr. D. A. Dragatogiannis for their comments that helped to improve the paper.

\section{References}

[1] R. Borsali and R. Pecora, Soft-Matter Characterization, Springer, New York, NY, USA, 2008.

[2] F. Carrillo, S. Gupta, G. W. Marshall et al., "Nanoindentation of polydimethylsiloxane elastomers: effect of crosslinking, work of adhesion, and fluid environment on elastic modulus," Journal of Materials Research, vol. 20, no. 10, pp. 2820 2830, 2005.

[3] M. R. Vanlandingham, "Review of instrumented indentation," Journal of Research of the National Institute of Standards and Technology, vol. 108, no. 4, pp. 249-265, 2003.

[4] D. Tranchida, A. Alexeev, J. Loos, and S. Piccarolo, "Accurately evaluating Young's modulus of polymers through nanoindentations: a phenomenological correction factor to 
the Oliver and Pharr procedure," Applied Physics Letters, vol. 89, no. 17, Article ID 171905, 2006.

[5] K. L. Mills, X. Zhu, M. D. Thouless, and S. Takayama, "The mechanical properties of a surface-modified layer on polydimethylsiloxane," Journal of Materials Research, vol. 23, no. 1, pp. 37-48, 2008.

[6] M. Meincken, T. A. Berhane, and P. E. Mallon, "Tracking the hydrophobicity recovery of PDMS compounds using the adhesive force determined by AFM force distance measurements," Polymer, vol. 46, no. 1, pp. 203-208, 2005.

[7] S. E. Cross, J. K. Gimzewski, Y. S. Jin, and J. Y. Rao, "Nanomechanical analysis of cells from cancer patients," Nature Nanotechnology, vol. 2, no. 12, pp. 780-783, 2007.

[8] J. Guck, "Optical deformability as an inherent cell marker for testing malignant transformation and metastatic competence," Biophysical Journal, vol. 88, no. 5, pp. 3689-3698, 2005.

[9] S. Suresh, "Elastic clues in cancer detection," Nature Nanotechnology, vol. 2, no. 12, pp. 748-749, 2007.

[10] S. Suresh, "Biomechanics and biophysics of cancer cells," Acta Materialia, vol. 55, no. 12, pp. 3989-4014, 2007.

[11] C. Rotsch and M. Radmacher, "Drug-induced changes of cytoskeletal structure and mechanics in fibroblasts: an atomic force microscopy study," Biophysical Journal, vol. 78, no. 1, pp. 520-535, 2000.

[12] S. E. Cross, R. Wong, J. Tondre, Y. S. Jin, J. K. Gimzewski, and J. Rao, "AFM-based analysis of human metastatic cancer cells," Nanotechnology, vol. 19, no. 38, pp. 384003-384011, 2008.

[13] O. Franke, A. M. Hodge, and M. Göken, "The nanoindentation of soft tissue: current and developing approaches," Journal of the Minerals Metals and Materials Society, vol. 60, no. 6, pp. 49-53, 2008.

[14] D. Ebenstein and L. A. Pruitt, "Nanoindentation of biological materials," Nano Today, vol. 1, no. 3, pp. 26-33, 2006.

[15] D. Ebenstein and K. J. Wahl, "A comparison of JKR-based methods to analyze quasi-static and dynamic indentation force curves," Journal of Colloid and Interface Science, vol. 298, no. 2, pp. 652-662, 2006.

[16] L. Cheng, X. Xia, L. E. Scriven, and W. W. Gerberich, "Spherical-tip indentation of viscoelastic material," Mechanics of Materials, vol. 37, no. 1, pp. 213-226, 2005.

[17] M. L. Oyen, "Spherical indentation creep following ramp loading," Journal of Materials Research, vol. 20, no. 8, pp. 2094 2100, 2005.

[18] http://www.lot-oriel.com/site/site_down/mm_fluidcell_en01 .pdf.

[19] A. Goruppa, S. A. Hayes, and F. R. Jones, "Dynamic nanoindentation as a tool for the examination of polymeric materials," Journal of Materials Research, vol. 19, no. 11, pp. 32983306, 2004.

[20] K. S. Kim, Z. Lin, P. Shrotriya, S. Sundararajan, and Q. Zou, "Iterative control approach to high-speed force-distance curve measurement using AFM: time-dependent response of PDMS example," Ultramicroscopy, vol. 108, no. 9, pp. 911920, 2008.

[21] S. Vasilakos, Characterization and study of drug release from polydimethylosiloxane/montmorillonite nanocomposites, thesis, School of Chemical Engineering, National Technical University of Athens, 2009.

[22] A. N. Chamos, C. A. Charitidis, S. Pantelakis, and A. Skarmoutsou, "An investigation on the high stress sensitivity of fatigue life of rolled AZ31 magnesium alloy under constant amplitude fatigue loading," Fatigue and Fracture of
Engineering Materials and Structures, vol. 33, no. 4, pp. 252265, 2010.

[23] K. Komvopoulos, L. A. Pruitt, and C. M. Klapperich, "Nanomechanical properties of polymers determined from nanoindentation experiments," Journal of Tribology, vol. 123, no. 3, pp. 624-631, 2001.

[24] D. Rowenhorst, X. Xia, W. W. Gerberich, and J. C. Grunlan, "Preparation and evaluation of tungsten tips relative to diamond for nanoindentation of soft materials," Review of Scientific Instruments, vol. 72, no. 6, pp. 2804-2810, 2001.

[25] C. H. Chiu and K. Zeng, "An analysis of load-penetration curves from instrumented indentation," Acta Materialia, vol. 49, no. 17, pp. 3539-3551, 2001.

[26] Y. Cao, W. Soboyejo, and D. Yang, "Nanoindentation method for determining the initial contact and adhesion characteristics of soft polydimethylsiloxane," Journal of Materials Research, vol. 20, no. 8, pp. 2004-2011, 2005.

[27] C. A. Charitidis and E. Koumoulos, "Nanomechanical properties and nanoscale deformation of PDMS nanocomposites," Plastics, Rubber and Composites. In press.

[28] W. C. Oliver and G. M. Pharr, "Improved technique for determining hardness and elastic modulus using load and displacement sensing indentation experiments," Journal of Materials Research, vol. 7, no. 6, pp. 1564-1580, 1992.

[29] F. Rossi and L. Sirghi, "Adhesion and elasticity in nanoscale indentation," Applied Physics Letters, vol. 89, no. 24, Article ID 243118, 2006.

[30] H. Y. Hou, N. K. Chang, S. H. Chang, and T. J. Chuang, Eds., Nanomechanics of Materials and Structures, 2006.

[31] N. K. Chang, C. C. White, P. L. Drzal, S. H. Chang, and M. R. Vanlandingham, "Viscoelastic characterization of polymers using instrumented indentation. II. Dynamic testing," Journal of Polymer Science, Part B, vol. 43, no. 14, pp. 1812-1824, 2005.

[32] J. K. Deuschle, H. M. Deuschle, G. Buerki, S. Enders, E. Arzt, and J. Michler, "In situ indentation testing of elastomers," Acta Materialia, vol. 56, no. 16, pp. 4390-4401, 2008.

[33] J. A. Greenwood, K. L. Johnson, S. A. S. Asif, and K. J. Wahl, "Oscillating adhesive contacts between micron-scale tips and compliant polymers," Journal of Colloid and Interface Science, vol. 296, no. 1, pp. 178-188, 2006.

[34] Y. X. Shen, P. J. Wei, and J. F. Lin, "Initial and adhesive contact between a diamond indenter and polydimethylsiloxane," Review of Scientific Instruments, vol. 79, no. 9, Article ID 096106, 2008.

[35] Y. Nakano and M. Sakai, "Elastoplastic load-depth hysteresis in pyramidal indentation," Journal of Materials Research, vol. 17, no. 8, pp. 2161-2173, 2002.

[36] R. F. Cook and M. L. Oyen, "Load-displacement behavior during sharp indentation of viscous-elastic-plastic materials," Journal of Materials Research, vol. 18, no. 1, pp. 139-150, 2003.

[37] K. H. Jeong, N. Chronis, G. L. Liu, and L. P. Lee, “Tunable microdoublet lens array," Optics Express, vol. 12, no. 11, pp. 2494-2500, 2004.

[38] R. Pelrine, R. Kornbluh, Q. Pei, and J. Joseph, "Highspeed electrically actuated elastomers with strain greater than 100\%," Science, vol. 287, no. 5454, pp. 836-839, 2000.

[39] B. J. Briscoe, K. S. Sebastian, and M. J. Adams, "Effect of indenter geometry on the elastic response to indentation," Journal of Physics D, vol. 27, no. 6, pp. 1156-1162, 1994.

[40] S. Yang, K. Zeng, and Y. W. Zhang, "Analysis of nanoindentation creep for polymeric materials," Journal of Applied Physics, vol. 95, no. 7, pp. 3655-3666, 2004. 
[41] A. C. Fischer-Cripps, "A simple phenomenological approach to nanoindentation creep," Materials Science and Engineering A, vol. 385, no. 1-2, pp. 74-82, 2004.

[42] CSM Instruments Applications Bulletin no. 22, 2006.

[43] J. B. Pethica and W. C. Oliver, "Tip Surface Interaction in STM and AFM," Physica Scripta T, vol. 19, pp. 61-66, 1987.

[44] P. Silberzan, S. Perutz, E. J. Kramer, and M. K. Chaudhury, "Study of the self-adhesion hysteresis of a siloxane elastomer using the JKR method," Langmuir, vol. 10, no. 7, pp. 24662470, 1994.

[45] G. Y. Choi, J. F. Kang, A. Ulman, W. Zurawsky, and C. A. Fleischer, "Acid-base interaction in the adhesion between two solid surfaces," Langmuir, vol. 15, no. 26, pp. 8783-8786, 1999.

[46] G. Y. Choi, S. Kim, and A. Ulman, "Adhesion hysteresis studies of extracted poly(dimethylsiloxane) using contact mechanics," Langmuir, vol. 13, no. 23, pp. 6333-6338, 1997.

[47] G. Y. Choi, A. Ulman, and W. Zurawsky, "Molecular weight effects in adhesion," Langmuir, vol. 15, no. 24, pp. 8447-8450, 1999.

[48] S. Kim, G. Y. Choi, A. Ulman, and C. A. Fleischer, "Effect of chemical functionality on adhesion hysteresis," Langmuir, vol. 13, no. 25, pp. 6850-6856, 1997.

[49] R. Mason, J. T. Koberstein, and J. A. Emerson, "Self-adhesion hysteresis in polydimethylsiloxane elastomers," Journal of Adhesion, vol. 80, no. 1-2, pp. 119-143, 2004.

[50] S. Perutz, J. M. Baney, E. J. Kramer, C. Cohen, and C. Y. Hui, "Investigation of adhesion hysteresis in po-ly(dimethylsiloxane) networks using the JKR technique," Journal of Polymer Science, Part B, vol. 36, no. 12, pp. 2129-2139, 1998.

[51] S. Perutz, E. J. Kramer, J. M. Baney, and C. Y. Hui, "Adhesion between hydrolyzed surfaces of poly(dimethylsiloxane) networks," Macromolecules, vol. 30, no. 25, pp. 7964-7969, 1997.

[52] J. P. Pickering and G. Vancso, "Influence of tip indentation depth on the adhesive behavior of viscoelastic polydimethylsiloxane networks studied by atomic force microscopy," Macromolecular Symposia, vol. 167, pp. 189-199, 2001.

[53] I. U. Vakarelski, M. Nakayama, A. Toritani, and K. Higashitani, "Deformation and adhesion of elastomer microparticles evaluated by AFM," Langmuir, vol. 17, no. 16, pp. 4739-4745, 2001.

[54] O. Noël, J. Schultz, G. Castelein, and M. Brogly, "In situ estimation of the chemical and mechanical contributions in local adhesion force measurement with AFM: the specific case of polymers," European Polymer Journal, vol. 40, no. 5, pp. 965-974, 2004.

[55] G. Gillies, P. Attard, and C. A. Prestidge, "An AFM study of the deformation and nanorheology of cross-linked PDMS droplets," Langmuir, vol. 18, no. 5, pp. 1674-1679, 2002.

[56] B. Derjaguin, Y. P. Toporov, and V. Müller, "Effect of contact deformations on the adhesion of particles," Journal of Colloid And Interface Science, vol. 53, no. 2, pp. 314-326, 1975.

[57] H. Takano, J. Kenseth, J. C. O'Brien, S. S. Wong, and M. D. Porter, "Chemical and biochemical analysis using scanning force microscopy," Chemical Reviews, vol. 99, no. 10, pp. 2845-2890, 1999.

[58] J. Song, D. Tranchida, and G. J. Vancso, "Contact mechanics of UV/ozone-treated PDMS by AFM and JKR testing: mechanical performance from nano- to micrometer length scales," Macromolecules, vol. 41, no. 18, pp. 6757-6762, 2008.

[59] M. Brogly, O. Noël, H. Awada, J. Schultz, and G. Castelein, "A nanoscale study of the adhesive contact," Comptes Rendus Chimie, vol. 9, no. 1, pp. 99-110, 2006.
[60] O. Vinogradova, H. J. Butt, G. E. Yakubov, and F. Feuillebois, "Dynamic effects on force measurements. I. Viscous drag on the atomic force microscope cantilever," Review of Scientific Instruments, vol. 72, no. 5, pp. 2330-2339, 2001.

[61] G. L. Miller, J. E. Griffith, E. R. Wagner, and D. Grigg, "A rocking beam electrostatic balance for the measurement of small forces," Review of Scientific Instruments, vol. 62, no. 3, pp. 705-709, 1991.

[62] J. Bryant, H. S. Kim, R. H. Decken, and Y. C. Cheng, "Surface force measurements on picometer and piconewton scales," Journal of Vacuum Science \& Technology A, vol. 8, pp. 35023505, 1990.

[63] D. Grigg, P. Russell, and J. E. Griffith, "Rocking-beam forcebalance approach to atomic force microscopy," Ultramicroscopy, vol. 42-44, pp. 1504-1508, 1992.

[64] J. Mertz, O. Marti, and J. Mlynek, "Regulation of a microcantilever response by force feedback," Applied Physics Letters, vol. 62, no. 19, pp. 2344-2346, 1993.

[65] S. P. Jarvis, A. Oral, T. P. Weihs, and J. B. Pethica, "A novel force microscope and point contact probe," Review of Scientific Instruments, vol. 64, no. 12, pp. 3515-3520, 1993.

[66] S. P. Jarvis, H. Yamada, S. I. Yamamoto, and H. Tokumoto, "Direct mechanical measurement of interatomic potentials," Nature, vol. 384, no. 6606, pp. 247-249, 1996.

[67] S. P. Jarvis and H. Tokumoto, "Measurement and interpretation of forces in the atomic force microscope," Probe Microscopy, vol. 1, no. 1, pp. 65-79, 1997.

[68] H. J. Butt, "A technique for measuring the force between a colloidal particle in water and a bubble," Journal of Colloid And Interface Science, vol. 166, no. 1, pp. 109-117, 1994.

[69] O. Vinogradova and R. G. Horn, "Attractive forces between surfaces: what can and cannot be learned from a jump-in study with the surface forces apparatus?" Langmuir, vol. 17, no. 5, pp. 1604-1607, 2001.

[70] J. B. Pethica and A. P. Sutton, "On the stability of a tip and flat at very small separations," Journal of Vacuum Science \& Technology A, vol. 6, pp. 2490-2494, 2008.

[71] H. J. Butt, G. Hüttl, O. Vinogradova, E. Müller, and A. Döppenschmidt, "Analysis of plastic deformation in atomic force microscopy: application to ice," Journal of Chemical Physics, vol. 113, no. 3, pp. 1194-1203, 2000.

[72] S. Gupta, F. Carrillo, C. Li, L. A. Pruitt, and C. M. Puttlitz, "Adhesion significantly affect elastic modulus determination of compliant polymeric materials in nanoindentation," Materials Letters, vol. 61, no. 2, pp. 448-451, 2007.

[73] E. Koumoulos, C. A. Charitidis, S. Vasilakos, and P. A. Tarantili, "Nanoindentation of nanocomposites polydimethylsiloxane elastomers," in Proceedings of the 7th Conference of Chemical Engineering, Patra, Greece, 2009.

[74] M. Stolz, U. Aebi, M. R. Vanlandingham, R. Raiteri, W. Baschong, and A. U. Daniels, "Dynamic elastic modulus of porcine articular cartilage determined at two different levels of tissue organization by indentation-type atomic force microscopy," Biophysical Journal, vol. 86, no. 5, pp. 32693283, 2004.

[75] E. A-Hassan, M. D. Antonik, W. Heinz et al., "Relative microelastic mapping of living cells by atomic force microscopy," Biophysical Journal, vol. 74, no. 3, pp. 1564-1578, 1998.

[76] P. K. Zysset, X. Edward Guo, C. Edward Hoffler, K. E. Moore, and S. A. Goldstein, "Elastic modulus and hardness of cortical and trabecular bone lamellae measured by nanoindentation in the human femur," Journal of Biomechanics, vol. 32, no. 10, pp. 1005-1012, 1999. 
[77] G. W. Marshall, R. Gallagher, M. Balooch, S. J. Marshall, and S. A. Gansky, "Mechanical properties of the dentinoenamel junction: AFM studies of nanohardness, elastic modulus, and fracture," Journal of Biomedical Materials Research, vol. 54, no. 1, pp. 87-95, 2001.

[78] A. B. Mann and J. B. Pethica, "Nanoindentation studies in a liquid environment," Langmuir, vol. 12, no. 19, pp. 4583 4586, 1996.

[79] P. L. Larsson and S. Carlsson, "On microindentation of viscoelastic polymers," Polymer Testing, vol. 17, no. 1, pp. 4975,1998

[80] W. W. Gerberich, D. E. Kramer, A. Strojny et al., "Elastic loading and elastoplastic unloading from nanometer level indentations for modulus determinations," Journal of Materials Research, vol. 13, no. 2, pp. 421-436, 1998.

[81] A. Strojny, X. Xia, W. W. Gerberich, and A. H. Tsou, "Techniques and considerations for nanoindentation measurements of polymer thin film constitutive properties," Journal of Adhesion Science and Technology, vol. 12, no. 12, pp. 1299-1321, 1998.

[82] K. L. Johnson, Contact Mechanics, Cambridge University Press, New York, NY, USA, 1985.

[83] S. Suresh, J. Alcalá, and A. E. Giannakopoulos, "Spherical indentation of compositionally graded materials: theory and experiments," Acta Materialia, vol. 45, no. 4, pp. 1307-1321, 1997.

[84] T. Chudoba, N. Schwarzer, and F. Richter, "Determination of elastic properties of thin films by indentation measurements with a spherical indenter," Surface and Coatings Technology, vol. 127, no. 1, pp. 9-17, 2000.

[85] J. S. Field and M. V. Swain, "Determining the mechanical properties of small volumes of material from submicrometer spherical indentations," Journal of Materials Research, vol. 10, no. 1, pp. 101-112, 1995.

[86] A. Lundkvist, E. Lilleodden, W. Siekhaus, J. Kinney, L. Pruitt, and M. Balooch, "Viscoelastic properties of healthy human artery measured in saline solution by AFM-based indentation technique," in Proceedings of the 6th Thin Films: Stresses and Mechanical properties Symposium, W. W. Gerberich, H. Gao, and J. E. Sundgren, Eds., pp. 353-358, Materials Research Society, Boston, Mass, USA, 1997.

[87] L. Cheng, L. E. Scriven, X. Xia, W. Yu, and W. W. Gerberich, "Flat-punch indentation of viscoelastic material," Journal of Polymer Science, Part B, vol. 38, no. 1, pp. 10-22, 2000.

[88] http://www.hysitron.com/LinkClick.aspx?fileticket=q8RUvWdlYg\%3D\&tabid=63.

[89] http://www.forestprod.org/adhesives09schirer.pdf.

[90] R. Akhtar, S. J. Eichhorn, and P. M. Mummery, "Microstructure-based finite element modelling and characterisation of bovine trabecular bone," Journal of Bionic Engineering, vol. 3, no. 1, pp. 3-9, 2006.

[91] F. Rico, P. Roca-Cusachs, N. Gavara, R. Farré, M. Rotger, and D. Navajas, "Probing mechanical properties of living cells by atomic force microscopy with blunted pyramidal cantilever tips," Physical Review E, vol. 72, no. 2, Article ID 021914, pp. 1-10, 2005.

[92] N. P. Daphalapurkar, C. Dai, R. Z. Gan, and H. Lu, "Characterization of the linearly viscoelastic behavior of human tympanic membrane by nanoindentation," Journal of the Mechanical Behavior of Biomedical Materials, vol. 2, no. 1, pp. 82-92, 2009.

[93] R. Pearce and G. J. Vancso, "Real-time imaging of melting and crystallization in poly(ethylene oxide) by atomic force microscopy," Polymer, vol. 39, no. 5, pp. 1237-1242, 1998.
[94] J. M. Schultz and M. J. Miles, "AFM study of morphological development during the melt-crystallization of poly(ethylene oxide)," Journal of Polymer Science, Part B, vol. 36, no. 13, pp. 2311-2325, 1998.

[95] J. K. Hobbs, Polymer Crystallization: Observations, Concepts and Interpretations, Springer, Berlin, Germany, 2003.

[96] S. N. Magonov and Y. Natalya, "Modern trends in atomic force microscopy of polymers," Macromolecules, vol. 35, pp. 5637-5649, 2003.

[97] J. K. Hobbs, N. Mullin, C. H. M. Weber, C. Vasilev, and O. E. Farrance, "Watching" processes in soft matter with SPM," Materials Today, vol. 12, no. 7-8, pp. 26-33, 2009.

[98] Y. Kamran and P.-L. Larsson, "Second-order effects at microindentation of elastic polymers using sharp indenters," Materials and Design, vol. 32, no. 6, pp. 3645-3653, 2011.

[99] Y. Y. Lim and M. M. Chaudhri, "Experimental investigations of the normal loading of elastic spherical and conical indenters on to elastic flats," Philosophical Magazine, vol. 83, no. 30, pp. 3427-3462, 2003.

[100] Y. Y. Lim and M. M. Chaudhri, "Indentation of rigid cones into conical holes molded in elastic blocks," Journal of Applied Physics, vol. 98, no. 7, Article ID 073518, pp. 1-9, 2005.

[101] V. P. Tsikourkitoudi, D. A. Dragatogiannis, and C. A. Charitidis, "Finite element modeling on nanoindentation and time dependent properties of soft matter," in Proceedings of the 8th Conference of Chemical Engineering, Athens, 2011.

[102] ANSYS Academic Research, Release V. 10.0, ANSYS Inc. Canonsburg, Pa, USA.

[103] Z. H. Xu and X. Li, "Effects of indenter geometry and material properties on the correction factor of Sneddon's relationship for nanoindentation of elastic and elastic-plastic materials," Acta Materialia, vol. 56, no. 6, pp. 1399-1405, 2008.

[104] ABAQUS version 6.6. Theory manual. ABAQUS, Inc., 2006.

[105] Z. H. Zhong, "Contact problems with friction," in Proceedings of the Numiform, Balkema, Rotterdam, 1989.

[106] J. L. Bucaille, E. Felder, and G. Hochstetter, "Experimental and three-dimensional finite element study of scratch test of polymers at large deformations," Journal of Tribology, vol. 126, no. 2, pp. 372-379, 2004.

[107] F. Wredenberg and P. L. Larsson, "Scratch testing of metals and polymers: experiments and numerics," Wear, vol. 266, no. 1-2, pp. 76-83, 2009.

[108] F. Wredenberg and P.-L. Larsson, "Delamination of thin coatings at scratching: experiments and numerics," Journal of Mechanics of Materials and Structures, vol. 4, no. 6, pp. 10411062, 2009.

[109] R. Schirrer, C. Gauthier, and H. Pelletier, "Influence of the friction coefficient on the contact geometry during scratch onto amorphous polymers," Wear, vol. 268, no. 9-10, pp. 1157-1169, 2010. 

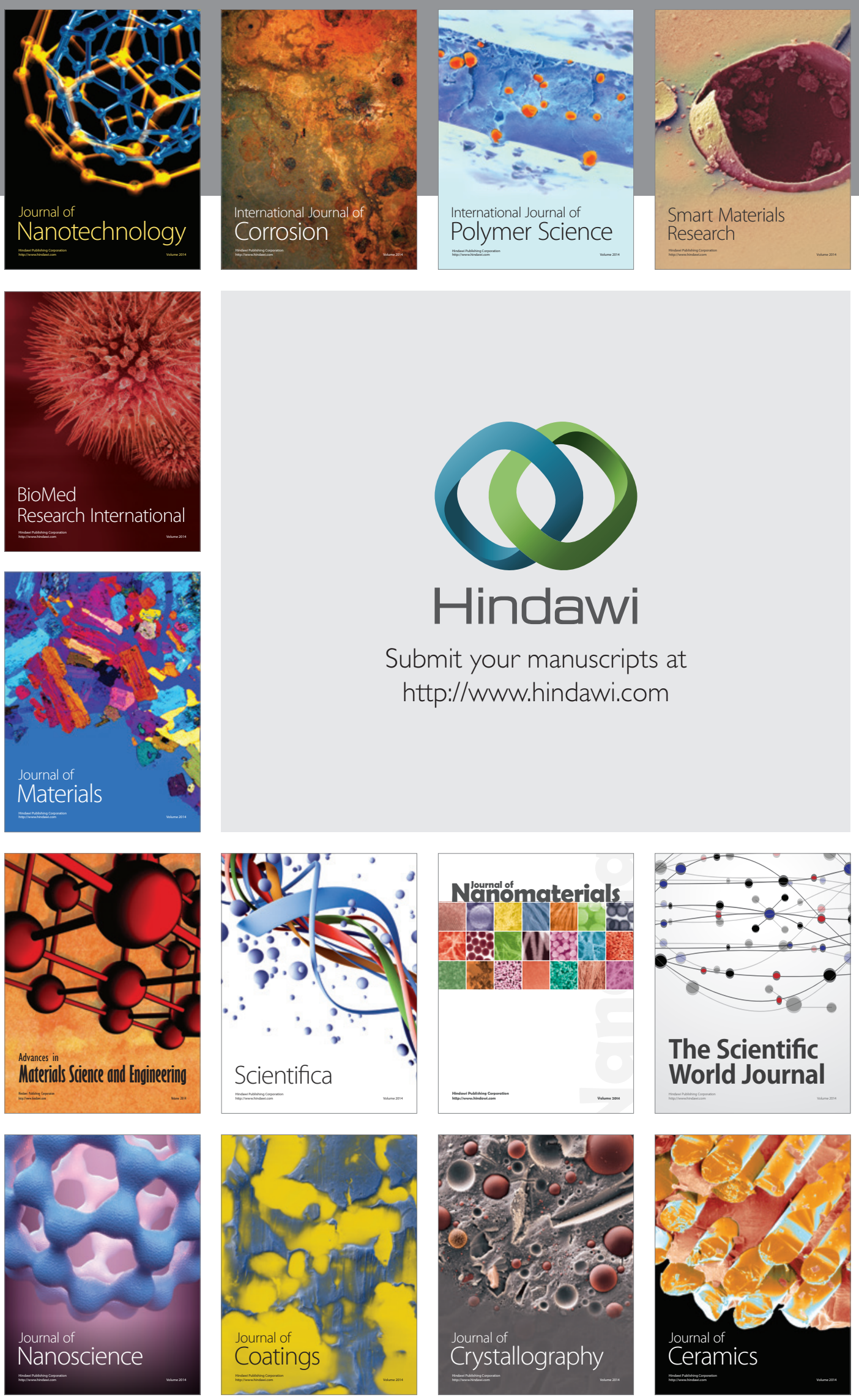

The Scientific World Journal

Submit your manuscripts at

http://www.hindawi.com

\section{World Journal}

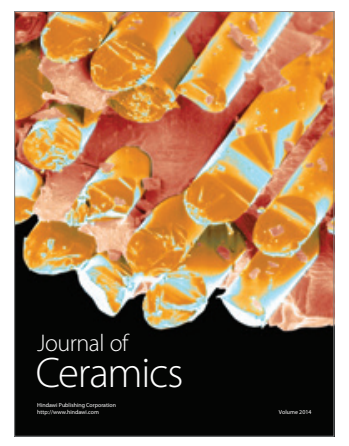

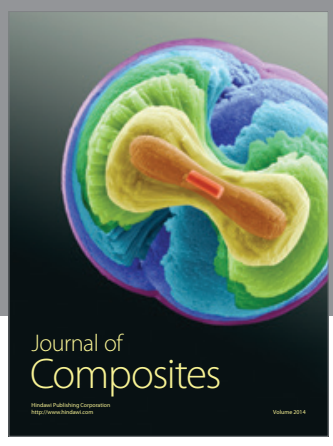
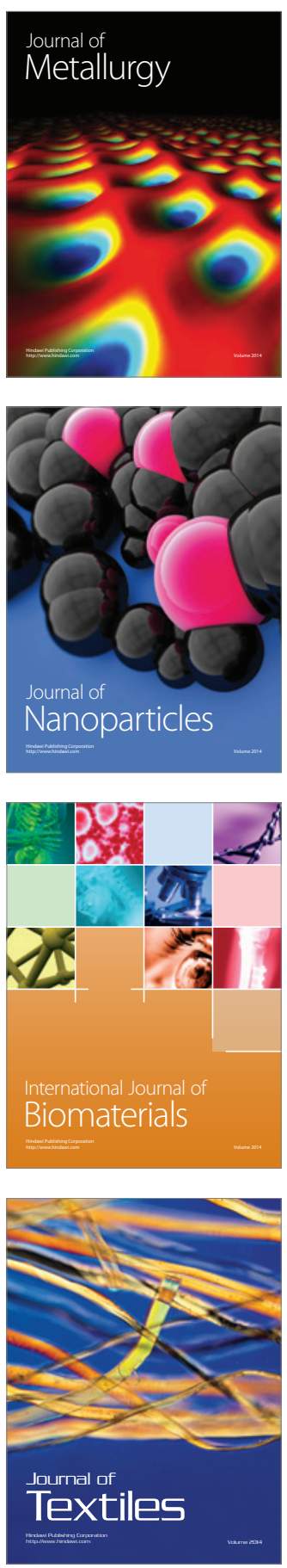